\title{
Challenges Facing Healthwatch, a New Consumer Champion in England
}

\author{
Pam Carter*, Graham Martin
}

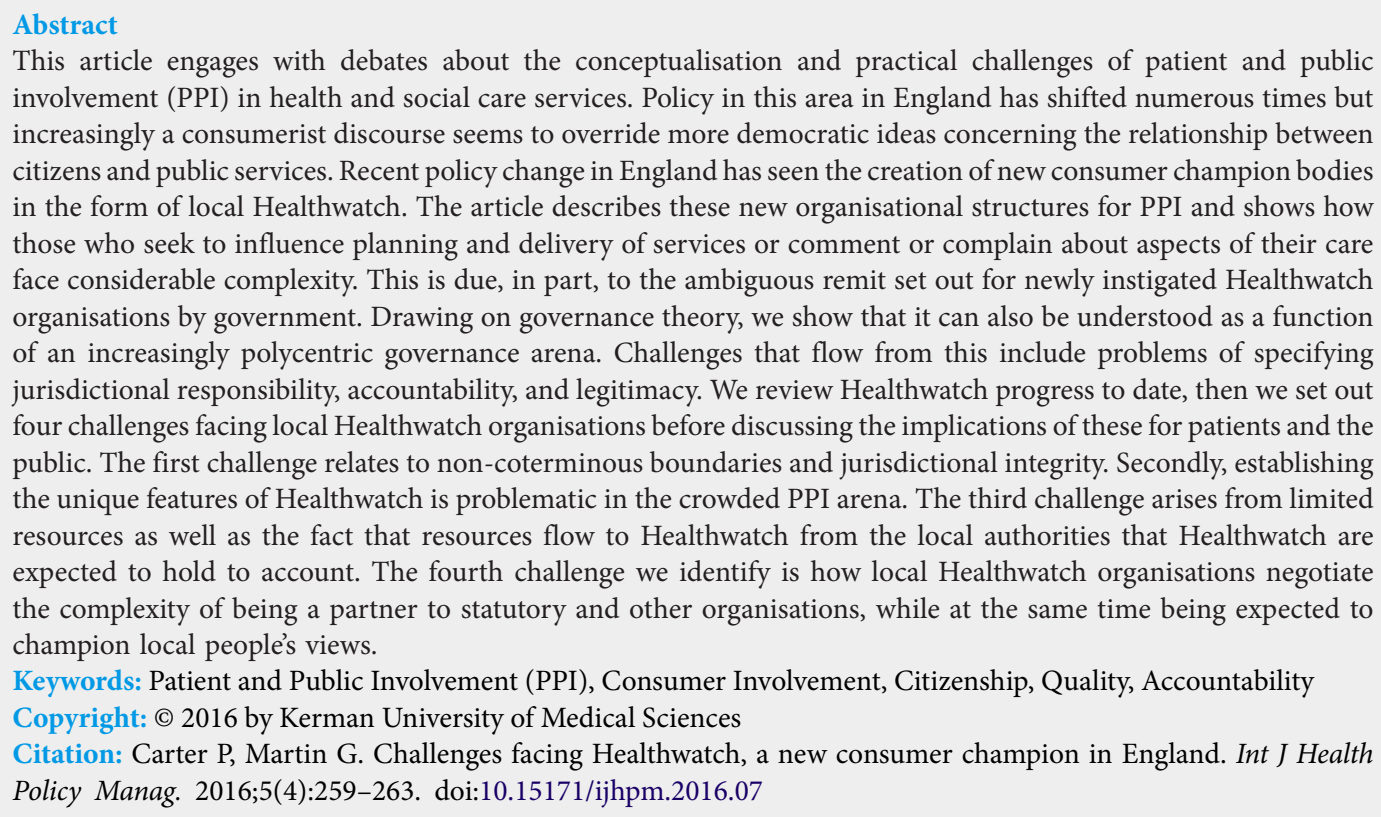

This article engages with debates about the conceptualisation and practical challenges of patient and public involvement (PPI) in health and social care services. Policy in this area in England has shifted numerous times but increasingly a consumerist discourse seems to override more democratic ideas concerning the relationship between citizens and public services. Recent policy change in England has seen the creation of new consumer champion bodies in the form of local Healthwatch. The article describes these new organisational structures for PPI and shows how those who seek to influence planning and delivery of services or comment or complain about aspects of their care face considerable complexity. This is due, in part, to the ambiguous remit set out for newly instigated Healthwatch organisations by government. Drawing on governance theory, we show that it can also be understood as a function of an increasingly polycentric governance arena. Challenges that flow from this include problems of specifying jurisdictional responsibility, accountability, and legitimacy. We review Healthwatch progress to date, then we set out four challenges facing local Healthwatch organisations before discussing the implications of these for patients and the public. The first challenge relates to non-coterminous boundaries and jurisdictional integrity. Secondly, establishing the unique features of Healthwatch is problematic in the crowded PPI arena. The third challenge arises from limited resources as well as the fact that resources flow to Healthwatch from the local authorities that Healthwatch are expected to hold to account. The fourth challenge we identify is how local Healthwatch organisations negotiate the complexity of being a partner to statutory and other organisations, while at the same time being expected to champion local people's views.

Keywords: Patient and Public Involvement (PPI), Consumer Involvement, Citizenship, Quality, Accountability

Copyright: @ 2016 by Kerman University of Medical Sciences

Citation: Carter P, Martin G. Challenges facing Healthwatch, a new consumer champion in England. Int J Health Policy Manag. 2016;5(4):259-263. doi:10.15171/ijhpm.2016.07

Article History:

Received: 29 September 2015 Accepted: 15 January 2016 ePublished: 21 January 2016

\section{Introduction}

Patient, carer, service-user, and public involvement or engagement (abbreviated to PPI hereafter) in health and care services has been much discussed in relation to themes of empowerment, efficiency and co-production. ${ }^{1-4}$ At the heart of most of these debates lie questions of power and responsibility. In a welfare state funded by general taxation, it has long been argued that citizens deserve a voice in how services are run. ${ }^{5}$ In the United Kingdom, publicly funded PPI dates back to 1973 when Community Health Councils (CHCs) were created. In 2002 CHCs were abolished and replaced by PPI Forums. These in turn were replaced in 2008 by local involvement networks (LINks). Successive reforms arguably demonstrate political commitment to, and sustained high-level interest in, PPI in its various organisational forms. However, especially in England since the Health and Social Care Act 2012, market mechanisms have become more prominent in the delivery of public services, giving rise to new consumerist approaches to PPI. In this article, we use governance theory as an analytical tool to understand the complex situation in which local Healthwatch organisations find themselves.

Briefly, governance theory distinguishes between governing via markets, hierarchies and networks that rely on mechanisms of choice, voice, and loyalty. ${ }^{1,6}$ Contemporary debates focus on the extent to which we see a shift from government to governance and on the implications of such a shift for democratic accountability. ${ }^{7,8}$ Recent debates have pointed in particular to the consequences of governance arrangements at a local level, where increasingly, multiple authorities with ambiguous relationships and lines of accountability may coexist. The 2012 Act included the establishment of 'Healthwatch'-a network of 152 local organisations across England, aligned to local authority boundaries, and a national body known as Healthwatch England. Healthwatch is to act as a "consumer champion," a description that seemingly endorses a market orientation. But the English National Health Service (NHS) remains a universal service free at the point of need; in the opening words of the NHS Constitution, it "belongs to the people." Correspondingly, some of the brief given to Healthwatch, to "strengthen the collective voice of local people," suggests a model of involvement premised more on citizenship than consumerism. In this article, we show that answering the question 'what is Healthwatch?' is not straightforward. We note variation between different local Healthwatch organisations, and argue that this ambiguity can be seen as a structural feature of the new system. We go on to analyse tensions facing Healthwatch managers and we discuss the implications of these for patients, carers and members of the public, for Healthwatch officers themselves, and for PPI in 
healthcare in England and beyond.

\section{Background}

Increasingly the NHS comprises multiple organisations including public, private and third-sector organisations. The Health and Social Care Act has led to further organisational complexity in England, abolishing some organisations and creating new ones, including new forums for strategic decision-making, notably local authority-hosted Health and Well-being Boards. ${ }^{11,12}$ Clinical commissioning groups (CCGs) are now responsible for commissioning many of the services that their local population will use, while social care remains the responsibility of local government. Healthwatch is positioned as the principal body responsible for representing the public's views in this new system. Local Healthwatch organisations have statutory responsibilities to seek the views of local people regarding health and care services and to pass on this information to those responsible for commissioning or providing care. ${ }^{1,9}$ They are expected to do this via direct relationships with commissioners and providers, and through their seat on the area's Health and Well-being Board. Healthwatch's role within this reorganised health and social care system raises perennial debates, familiar from the literature, about the proper role for PPI, including questions about where the power lies. ${ }^{1,13}$

The seat granted to Healthwatch at Health and Well-being Boards implies they might have sway, but others have suggested that the influence of Health and Well-being Boards on commissioning decisions will be weak..$^{7,14}$ Moreover, Healthwatch is not the only organisation with responsibility for PPI: NHS organisations are still required to undertake their own PPI activities, and may or may not choose to draw on the services of Healthwatch in delivering these, while general practices are also expected to have their own PPI structures. ${ }^{15}$ In addition, the PPI arena is becoming further crowded by a range of independent organisations claiming to offer patients' views on health and social care, often deploying Web 2.0-enabled services to allow people to log their opinions and describe their experience of care, producing TripAdvisorstyle ratings. ${ }^{16,17}$ The system is thus difficult to navigate and whether such forms of PPI result in influence is unclear. If action does not result, apparent avenues for voice might turn out to be culs-de-sac or a "dialogue of the deaf." 18
What Is Healthwatch?

Healthwatch is described as "the national consumer champion in health and care." Commissioned by local government, local Healthwatch are independent bodies, expected to involve volunteers in their activities and in their governance arrangements. However, local Healthwatch organisational forms vary: some nest within host organisations, usually belonging to the voluntary sector; others are constituted as hybrid private-voluntary sector Community Interest Companies. ${ }^{19}$ Some have charitable status as well as a trading arm. Nonetheless there is a core set of activities that each local Healthwatch must deliver. These are set out in Table extracted from Healthwatch guidance. ${ }^{20}$

While many of the activities in Table could contribute to local voice and citizenship, others, such as "providing information so choices can be made," align with a consumerist agenda and promote choice rather than voice. Local government and local Healthwatch negotiate the terms of their contract and in addition to the activities in Table, many Healthwatch organisations exercise their right to undertake 'enter and view' inspections of providers' establishments. ${ }^{19}$ Some Healthwatch also provide advocacy and/or complaints services, but where these are commissioned and delivered separately, Healthwatch are expected to direct patients to these services. Therefore, the answer to the question of what Healthwatch is may vary, presenting confusion to local people. The Healthwatch 'brand' was intended, in part, to answer criticisms of the differential profile and visibility of Healthwatch's predecessor organisations, ${ }^{9}$ but as Carter's work on policy branding shows, ${ }^{21}$ brands may conceal a wide variation in what is actually provided in local implementation.

\section{Tensions Facing Local Healthwatch}

The challenges facing Healthwatch, however, do not just derive from variations in the constitution and core activity of different Healthwatch organisations. Rather, the remit set out for them by government, as outlined above, and their places within local healthcare economies, create tensions for local Healthwatch that might be characterised as structural in nature. We examine four such tensions which, we suggest, pose a challenge for local Healthwatch as they seek to establish a legitimate place for themselves in local governance arrangements. Our analysis derives from an examination of the

Table. Legally Mandated Healthwatch Activities

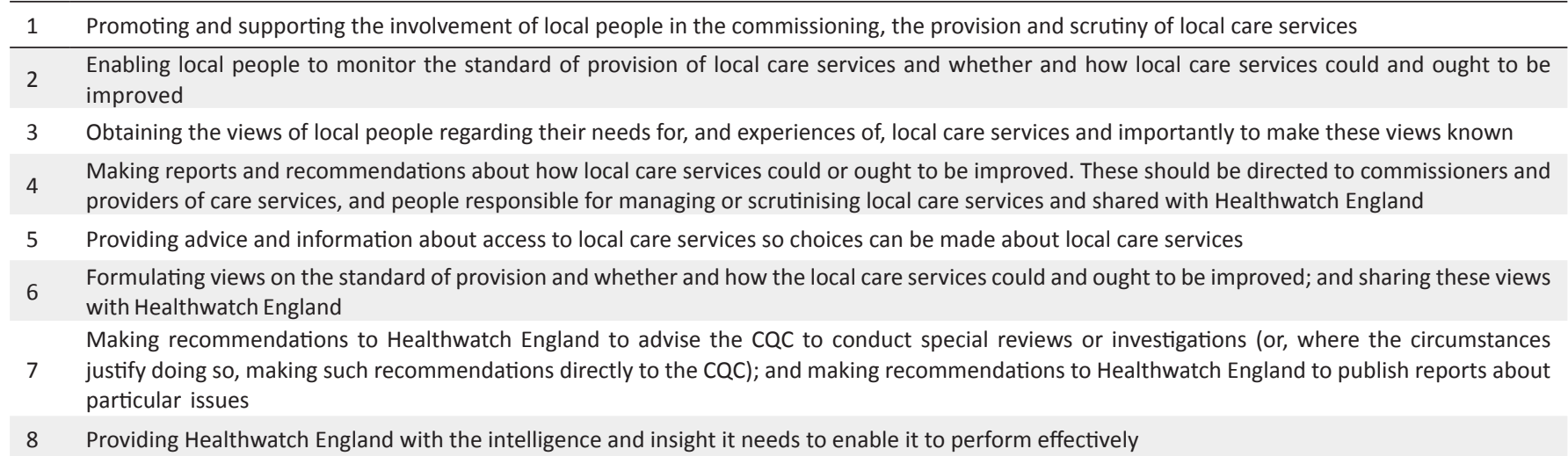

Abbreviation: CQC, Care Quality Commission.

Source: Healthwatch England, http://www.healthwatch.co.uk/sites/healthwatch.co.uk/files/a-guide-to-the-legislation-affecting-local_healthwatch.pdf. 
policy literature and Healthwatch documents, and informed by interview data from a study of PPI in one English region and by discussion with professional staff directly involved in the system. It is not based on a formal qualitative analysis of documentary or empirical data, and should be interpreted accordingly. We relate these to theoretical perspectives on contemporary governance that help to shed light on the contours of the challenge faced.

\section{Jurisdictional Integrity}

The notion of jurisdictional integrity has been theorised by Skelcher, who draws attention to the importance of recognisable boundaries to the legitimate exercise of power, so that citizens can be clear how to hold decisionmakers to account. ${ }^{8}$ Where decision-making goes beyond the boundaries of a single autonomous organisation with clearly defined geographical sovereignty and extends to affiliations, partnerships or networks of overlapping agencies, this distributed form of authority results in 'polycentric governance.' Local authority areas may not be coterminous with CCGs' or provider organisations' catchments; consequently some local Healthwatch must deal with multiple commissioners and providers that have different administrative and geographical boundaries. Moreover, organisations (such as local authorities) with conventional lines of accountability, defined by geographical boundaries and deriving legitimacy from the democratic mandate provided by the population within those boundaries, may not automatically accept the more "amorphous and fluid" governance arrangements of these new organisations. ${ }^{22}$ The jurisdictional misalignment of Healthwatch with key NHS organisations with which they are to interact-as Skelcher has it, the absence of "a rationally ordered hierarchy of governmental [sic] at different spatial scales"8-is compounded by rather loose arrangements for accountability between Healthwatch and other organisations. Although CCGs are required to consult with Healthwatch, there is no requirement to accept their recommendations, and so Healthwatch's ability to hold decision-makers to account is limited. Health and Well-being Boards may formally ratify joint health and social care plans but there are indications that this is not necessarily where power lies or where major decisions are made. ${ }^{14}$ The result is a situation where "authority is diffuse and ill-defined because of the complexity of spatial patterning, functional overlays between jurisdictions, variable density of political spaces, and differential coupling between organizations."

This may have consequences for local Healthwatch's ability to exert influence, as well as for local people's ability to hold decision-makers to account. An example of such complex governance can be found in the NHS Five Year Forward View, ${ }^{23}$ a key national strategy document that sets out a vision of integrated services delivering new models of care that transcend catchments and work across organisational boundaries. In addition to this challenge from above, the 'new localism' agenda seeks to place greater power and responsibility beyond and below the level of local government. ${ }^{24}$ Polycentric governance, then, means that a health and social care economy is not a hierarchically ordered system accountable through traditional local democratic representation, but an increasingly complex network of relationships of influence. ${ }^{3}$ This poses challenges to Healthwatch's remit to represent the views of local populations, its claims to legitimacy, and its ability to exert influence.

\section{Establishing Credibility: Does Local Healthwatch Have a 'USP'?}

Local Healthwatch have oversight of all local publicly funded health and social care services. They have already produced reports based on local data and presented these to Healthwatch England and to local bodies including commissioners. However, a recent report by the King's Fund noted "challenges between the process of creating evidence and then influencing change." 19 Perhaps more importantly, Healthwatch is not the only body that undertakes this kind of work: indeed, many of the functions listed in Table are also covered by other bodies, from the local voluntary sector, through statutory organisations, to large for-profit companies. In terms of collating and analysing public opinion and patient experiences, for example, there are besides Healthwatch many other sources of patient opinion, including the Friends and Family Test, ${ }^{25}$ National Voices ${ }^{26}$ and a range of private-sector providers of analytics of patient experience. ${ }^{17}$

CCGs and NHS providers are required to involve patients in decision-making. While they are advised to consult their local Healthwatch, ${ }^{9}$ they may conduct consultation and participation exercises unilaterally, thus potentially duplicating effort and undermining Healthwatch. Local authority overview and scrutiny committees also retain an important role in scrutinising local health and social care services, ${ }^{27}$ particularly major service changes. Voluntarysector organisations have a history of engaging with patients and the public and liaising with statutory services, ${ }^{3}$ and in some cases may be in direct competition with Healthwatch for funding for activities such as gathering information on the needs and preferences of local populations. There is a need, therefore, for further examination of the complex inter-personal and inter-organisational relationships that Healthwatch are negotiating in seeking to find a unique role in local health and social care economies. Longstanding questions about citizen voice and consumer choice persist. ${ }^{4} \mathrm{~A}$ more recent phenomenon is a commodified form of PPI that is enacted in a marketplace characterized by an increasing plurality of suppliers, with varied and sometimes opaque mechanisms for representation.

\section{Resources and Dependencies}

A recent report notes that local Healthwatch operate on a modest budget, given their obligation to serve and represent their local population. ${ }^{19}$ Local authorities face increasingly constrained budgets, including significant real-terms decreases in funding in recent years, and because they are commissioned by local authorities, Healthwatch may be vulnerable to these pressures. Indeed, some have already seen their budgets 'skimmed.'27 Resource-dependency theory ${ }^{28}$ suggests that local Healthwatch are in compromised contractual relationships, expected to scrutinise services that are provided by their main source of funding-or, to put it colloquially, 'bite the hand that feeds them.' There is a delicate balance to be achieved between having a seat at the 
table in order to exert influence and acting independently as a critic. ${ }^{18,19}$ Given these constraints, there are questions about the extent to which local stakeholders perceive local Healthwatch as independent and what strategies are adopted by local Healthwatch to balance these pressures in involving patients in volunteering and in scrutinising the quality of service provision.

4. Healthwatch as a Partner in Local Planning and Coordination of Services

One rationale for PPI is to enhance effectiveness by ensuring that the views of those who use services are reflected in the design and co-production of services. In other words, it is contended that involvement can be instrumentally useful by improving service quality, appropriateness and efficiency. ${ }^{29}$ This efficiency rationale exists alongside a discourse of user empowerment, which may be more challenging to healthcare managers and policy-makers. ${ }^{27}$

A very strong and, on the surface, compelling narrative in NHS England's Five Year Forward View suggests that the current 'crisis' of funding, inefficiencies and demographic pressures means that there is no choice but to radically modernise an NHS that was founded in a different era to meet different needs. The document claims that "there is now quite broad consensus on what a better future should be." ${ }^{23}$ A challenge for local Healthwatch is to decide on the extent to which they act as an equal partner within this claimed consensus. Close working with decision-makers in health and social care might seem to compromise Healthwatch's role as independent scrutineer, especially if plans prove to be contentious or unpopular with local people. A document co-authored by three key organisations in the governance of English healthcare-Monitor, the Trust Development Authority, and NHS England-on the plight of 'challenged health economies' discusses PPI in terms of the "legal obligation to show how the public's views are being taken into account and included in the options development" and the need for "a speedy and effective consultation process that limits the risk of judicial review. ${ }^{30}$ Maintaining independence and influence at a time of such pressure to act swiftly and instigate fundamental change will undoubtedly be a challenge for Healthwatch, as they seek to avoid incorporation into the system they are expected to hold to account.

\section{Concluding Comments}

The challenges we have identified draw specifically on the English experience, but have implications for other contexts where debates focus on whether access to quality healthcare is a universal entitlement guaranteed to citizens or a consumer good to be provided by the market. ${ }^{31}$ Policy-makers in other systems might learn from the profusion of functions and forms of PPI, with attendant potential for confusion that has arisen. Individual patients, citizens and their representatives are negotiating competing roles as citizens, consumers and co-producers. ${ }^{4}$ Simultaneously we are witnessing the rise of increasingly commodified sources of 'patient experience. ${ }^{17}$ Internationally, distinctions between the market, the state and civil society have become increasingly blurred, and PPI worldwide operates within this liminal space. ${ }^{6,8}$ Healthwatch's role of consumer champion and the constitution of some
Healthwatch as income-generating Community Interest Companies $^{32}$ sits awkwardly alongside more traditional expectations of citizen rights, a public service ethos and democratic accountability.

We do not wish to overemphasise the structural constraints facing Healthwatch. Many theorists of governance as well as scholars of PPI highlight the agency of local actors and their ability to mediate constraints through exerting influence, brokering trust within networks and translating top down policy mandates in innovative ways. ${ }^{6,12}$ Moreover, if there is one lesson to be learned from the recent history of rapid change in organisational arrangements for PPI in English healthcare, it is that new governance structures require time to 'bed in' and provide a basis for functional relationships. We suggest that collective work among Healthwatch organisations, perhaps orchestrated by Healthwatch England, may help to maximise their influence despite the constraints they face. For example, a recently published document reports on work towards a set of quality standards for Healthwatch and provides several interesting examples of local Healthwatch exerting influence at local level..$^{33}$ This report also demonstrates how some local Healthwatch activities have translated into national level influence by using the escalation mechanism that is in place within the Healthwatch network. New models of service delivery may provide opportunities for novel forms of participatory or deliberative democracy. ${ }^{1,34}$ Nevertheless, the structural features of the new system we have identified will make this process challenging for Healthwatch and health and social care providers and commissioners.

Our analysis shows that local Healthwatch are negotiating with multiple stakeholders and competing for legitimacy within governance arrangements that comprise markets, hierarchies and networks. In this complex system of polycentric governance and in a crowded PPI environment, they must try to establish themselves as the 'go-to' organisation for patients and the public. Healthwatch's 'constituents' include 'seldom-heard' groups who deserve a voice, as well as more empowered individuals who seek information about their healthcare choices. Further research might focus on how these tensions manifest in practice and how local Healthwatch are negotiating positions of influence and trust.

\section{Acknowledgements}

This article derives from a study funded by the National Institute for Health Research (NIHR) Collaboration for Leadership in Applied Health Research and Care (CLAHRC) East Midlands, London, UK. The views expressed are those of the author(s) and not necessarily those of the NHS, the NIHR or the Department of Health. We acknowledge support and advice from our stakeholders, including our PPI Advisory Group members. We are grateful for helpful comments and suggestions on the draft article from Rosie Newbigging, Chief Executive Officer, Healthwatch Northamptonshire, Vandna Gohil, Director, Healthwatch Leicestershire, and one other anonymous Healthwatch officer.

Ethical issues

Not applicable.

Competing interests

Authors declare that they have no competing interests. 
Authors' contributions

PC produced the first draft, GM commented on and revised several drafts. Both authors approve the final manuscript.

\section{References}

1. Hudson B. Public and patient engagement in commissioning in the English NHS: an idea whose time has come? Public Management Review. 2014;17(1):1-16.

2. Taylor J, Tritter JQ. Local Involvement Networks: Learning From the Early Adopter Programme Final Report. Coventry: Warwick University; 2007.

3. Martin G. The third sector, user involvement and public-service reform: a case study in the co-governance of health-service provision. Public Adm. 2011;89(3):909-932.

4. Dent M, Pahor M. Patient involvement in Europe-a comparative framework. J Health Organ Manag. 2015;29(5):546-555. doi:10.1108/JHOM-05-2015-0078

5. Martin GP. Representativeness, legitimacy and power in public involvement in health-service management. Soc Sci Med. 2008;67(11):1757-1765. doi:10.1016/j.socscimed.2008.09.024

6. Newman J, Clarke J. Publics, Politics and Power. London: Sage; 2009.

7. Peckham S. Accountability in the UK healthcare system: an overview. Healthcare Policy. 2014; 10:154-162.

8. Skelcher C. Jurisdictional integrity, polycentrism, and the design of democratic governance. Governance. 2005;18(1):89-110.

9. Department of Health. Local Healthwatch: A strong voice for people - the policy explained. London: Department of Health; 2012.

10. Department of Health. The NHS Constitution for England. London: Department of Health; 2013.

11. Petsoulas C, Peckham S, Smiddy J, Wilson P. Primary care-led commissioning and public involvement in the English National Health Service. Lessons from the past. Prim Health Care Res Dev. 2015; 16 (3):289-303. doi:10.1017/S1463423614000486

12. Tritter JQ, Koivusalo M. Undermining patient and public engagement and limiting its impact: the consequences of the Health and Social Care Act 2012 on collective patient and public involvement. Health Expect. 2013;16(2):115-118. doi:10.1111/ hex.12069

13. Barnes M. Alliances, contention and oppositional consciousness: can public participation generate subversion? In: Barnes M, Prior D, eds. Subversive Citizens. Bristol: Policy Press; 2009.

14. Coleman A, Checkland K, Segar J, Mcdermott I, Harrison S, Peckham S. Joining it up? health and wellbeing boards in English local governance: evidence from clinical commissioning groups and shadow health and wellbeing boards. Local Government Studies. 2014;40(4):560-580.

15. Smiddy J, Reay J, Peckham S, Williams L, Wilson P. Developing patient reference groups within general practice: a mixedmethods study. $\mathrm{Br} J$ Gen Pract. 2015;65(632):177-183. doi:10.3399/bjgp15X683989

16. Light K, Stirk L, Wright K. Patient opinion. J Health Ser Res Policy. 2010;15(3):190-192. doi:10.1258/jhsrp.2010.010020
17. Lupton D. The commodification of patient opinion: the digital patient experience economy in the age of big data. Sociol Health IIIn. 2014;36(6):856-869. doi:10.1111/1467-9566.12109

18. Scott JC. Seeing Like a State. New Haven: Yale University Press; 1998.

19. Gilbert H, Dunn P, Foot C. Local Healthwatch: Progress and Promise. London: The King's Fund; 2015.

20. Healthwatch England. Understanding the Legislation: An overview of the legal requirements for local Healthwatch. http://www.healthwatch.co.uk/sites/healthwatch.co.uk/ files/20130822_a_guide_to_the_legislation_affecting_local_ healthwatch_final.pdf. Published 2015.

21. Carter P. Governing welfare reform symbolically: evidence based or iconic policy? Crit Policy Stud. 2011;5(3):247-263. doi:10.108 0/19460171.2011.606298

22. Barnes M, Newman J, Knops A, Sullivan H. Constituting 'the public' in public participation. Public Adm. 2003;81(2):379-399. doi:10.1111/1467-9299.00352

23. Department of Health. NHS five year forward view. http://www. england.nhs.uk/wp-content/uploads/2014/10/5yfv-web.pdf. Accessed May 20, 2015.

24. Clarke N, Cochrane A. Geographies and politics of localism: The localism of the United Kingdom's coalition government. Polit Geogr. 2013;34:10-23.

25. Dixon-Woods M, Minion JT, McKee L, Willars J, Martin G. The friends and family test: A qualitative study of concerns that influence the willingness of English National Health Service staff to recommend their organisation. J R Soc Med. 2014;107(8):318325 .

26. Foot C, Gilburt H, Dunn P, et al. People in Control of Their Own Health and Care. London: The King's Fund; 2014.

27. Baggott $R$, Jones $K$. The big society in an age of austerity: threats and opportunities for health consumer and patients' organizations in England. Health Expect. 2015;18(6):2164-2173. doi:10.1111/hex.12185

28. Pfeffer J, Salancik GR. The External Control of Organizations. Redwood: Stanford University Press; 2003.

29. Martin GP. 'Ordinary peopleonly': Knowledge, representativeness, and the publics of public participation in healthcare. Soc Health IIIn. 2008;30(1):35-54. doi:10.1111/j.1467-9566.2007.01027.x

30. TDA, Monitor, NHS England. Making local health economies work better for patients. London: NHS England; 2014.

31. Buetow S. Getting the balance right: thick and thin approaches to harmonizing state particularism and the human right to health. Health Expect. 2012;15(4):441-448. doi:10.1111/j.13697625.2011.00666.x

32. Haugh $\mathrm{H}$, Peredo AM. Critical narratives of the origins of the community interest company. In: Hull R, ed. Critical Perspectives on the Third Sector. Bradford; Emerald: 2011.

33. Gamsu M, Chapman J, Miller S. Developing Quality Statements for Local Healthwatch. Leeds: Leeds Beckett University; 2015.

34. Barnes M, Newman J, Sullivan H. Discursive arenas: deliberation and the constitution of identity in public participation at a local level. Soc Mov Stud. 2006;5(3):193-207. 